\title{
EFL Students' Perceptions of Google Docs as an Interactive Tool for Learning Writing
}

\author{
Khaled ALDOSSARY ${ }^{1}$ \\ ${ }^{1}$ College of Languages \& Translation, Department of English Language \& Translation, Saudi Arabia \\ Correspondence: Khaled Salem Aldossary, Department of English Language and Translation, College of \\ Languages and Translation, King Saud University, Riyadh, Saudi Arabia. E-mail: kdossary@ksu.edu.sa
}

Received: January 2, 2022

Accepted: February 14, 2022 Online Published: February 20, 2022

doi:10.5539/ijel.v12n2p60

URL: https://doi.org/10.5539/ijel.v12n2p60

\begin{abstract}
The present study aimed to explore the perceptions of Saudi tertiary-level students toward using Google Docs as a learning tool in English as a foreign language (EFL) writing classes. Adopting a quantitative approach, 164 Saudi EFL students studying writing at three different academic levels completed a questionnaire about their perceptions of utilizing Google Docs as an alternative learning platform to learn writing and interact with teachers and peers. The findings showed that the participants perceived Google Docs useful and interesting. They also indicated that Google Docs could establish a collaborative learning environment. Their use enhanced student-teacher and student-student interactions, improved students' overall writing skills, and encouraged constructive peer-to-peer discussions. The study suggests that Google Docs plays a significant role in promoting learners' motivation and involvement in learning second language writing. It concludes with some limitations and provides recommendations for future research.
\end{abstract}

Keywords: EFL writing, collaborative learning, Google Docs, learners' interaction

\section{Introduction}

Writing in English as a foreign language (EFL) is a complex, challenging, and non-linear process (Suvin, 2020) that requires writers to engage various cognitive skills (Crossley \& McNamara, 2016). Such non-linear processes are characterized by continuous planning, drafting, and revision (Ransdell \& Barbier, 2002). As writing is a cognitive activity, teachers play an essential role in guiding students to improve their writing skills (Javadi-Safa, 2018). Additionally, in recent years, the integration of technology into writing classes has significantly benefited writing instruction. Furthermore, the vast spread of the global coronavirus disease 2019 (COVID-19) pandemic has highlighted the significance of using technology-assisted interactive learning platforms to allow continuous teaching and learning. The use of these interactive resources, particularly in writing classes, has created opportunities for teachers to adapt and cater to the learning needs of various students (Lee \& Hassell, 2021). Importantly, one of the online tools commonly used in writing classes is Google Docs.

Over the past decade, the use of Google Docs has facilitated the creation of online interactive learning environments for EFL writing learners (Alharbi, 2019). As a web-based synchronous tool, Google Docs can be used across the entire writing process, including task planning, negotiation, text co-construction, editing, and producing the final written product, in a reciprocal and participatory manner $(\mathrm{Li}, 2018)$. Therefore, this platform provides opportunities for students to collaborate on writing tasks and for teachers to review, edit, and comment on students writing assignments in real-time. These contributions and any changes made to the document can be tracked through the revision history feature. Another feature of Google Docs is that they provide opportunities for extended out-of-class interactions, through which learners can work on their writing tasks with ease and efficiency (Woodrich \& Fan, 2017), and teachers can access these writing tasks at any time.

However, learners may have different views on its efficacy despite the widely reported benefits of Google Docs in writing classes (e.g., Jiang \& Eslami, 2021; Khalil, 2018). Indeed, although the literature has demonstrated various advantages of utilizing technology for teaching and learning writing, there is limited research examining students' perceptions of using Google Docs in university writing classes in Saudi Arabia. Therefore, it is vital to explore learners' perceptions of using Google Docs in writing classes, as this represents an important factor that may influence their motivation and participation. The present study attempts to explore tertiary-level students' perceptions of using Google Docs as an interactive educational tool in writing classes. The study particularly 
aims to address the following research questions:

1) What are Saudi tertiary students' perceptions of using Google Docs as a learning platform in EFL writing classes?

2) What are Saudi tertiary students' perceptions of using Google Docs to engage with their teachers in EFL writing classes?

3) What are Saudi tertiary students' perceptions of using Google Docs to engage with their peers in EFL writing classes?

\section{Literature Review}

Among educators, the use of technology in education is gaining popularity for providing motivating and innovative learning environments for EFL learners. Web 2.0 technologies currently implemented in classrooms include Learning Management Systems (LMS), wikis, Google Docs, etc. Integrating technology into classrooms can provide alternative and, perhaps, motivating (Reyna, 2013) means for instructors and students to work collaboratively in virtual environments. Furthermore, such integration has recently increased due to the sudden shift to online learning during the COVID-19 pandemic. This rapid shift has also led to increased accessibility of Web 2.0 tools for EFL teaching and learning, such as Google Docs in EFL writing classes, to fulfill the intended pedagogical objectives.

According to Chinnery (2008), Google Docs is a productive tool that can be used to design creative learning activities. For instance, learners can work on joint tasks without the restrictions often imposed by traditional face-to-face teaching methods (Perron \& Sellers, 2011), and teachers can monitor and engage with students during the task composition process. These features of Google Docs have captured second language (L2) researchers' attention, as they offer great potential for language learning in EFL classrooms (Al-Chibani, 2016; Ishtaiwa \& Aburezeq, 2015; Jeong, 2016; Kessler et al., 2012; Seyyedrezaie et al., 2016; Suwantarathip \& Wichadee, 2014; Liu et al., 2014; Liu \& Lan, 2016; Mudawe, 2018; Zhou et al., 2012).

A qualitative study by Al-Chibani (2016) examined the impact of integrating Google Docs into learning on students' engagement and motivation in EFL writing classes with a group of 25 undergraduates from a private university in Lebanon. Utilizing a questionnaire to explore students' perceptions of Google Docs, the findings showed that the students had positive attitudes toward using Google Docs for writing assignments. The findings also indicated that Google Docs was easy to use and provided opportunities for students to communicate with each other and the teacher. Importantly, this reciprocal communication positively influenced students' motivation and self-confidence. Zhou et al. (2012) reported similar findings, as the participants in their study reported that Google Docs allowed them to communicate with each other more easily and with less anxiety. Taken together, the past research indicates that the use of Google Docs positively influences motivation and communication in EFL learning contexts.

Furthermore, Ishtaiwa and Aburezeq (2015) conducted a mixed-methods study with 176 students to examine the impact of Google Docs on enhancing collaboration. The findings showed that Google Docs was perceived as valuable for encouraging various collaborative behaviors, such as entertainingly sharing knowledge, comparing students' work with that of other classmates, engaging in discussions, and providing and receiving feedback. Similar findings were also reported in Jeong's (2016) study, as Google Docs was perceived as an interactive tool that could contribute to enhancing students' knowledge. Indeed, Jeong (2016) reported that the 20 EFL college students in the sample enjoyed their experience of writing tasks using Google Docs, as these tasks promoted interaction and collective knowledge formation. Additionally, the study indicated that using Google Docs allowed the students to better organize their written tasks due to the accessibility and interactivity of the platform. The students recognized the value of instant feedback from the instructor and exchanging feedback with peers. A study by Kessler et al. (2012) examined 38 ESL students' perceptions of utilizing Google Docs to specifically prepare them for academic research. The researchers particularly explored the students' perceptions of the changing nature of collaborative writing and the influence of Google Docs on their writing. The findings indicated that the students recognized the different aspects of Google Docs as a collaborative tool, as well as that they appreciated this collaboration, as each group member played an essential role in the learning process. In this study, the students also felt that they contributed equally to the tasks and that such contributions facilitated all students' writing through the feedback provided on the virtual platform. Overall, these studies indicate that Google Docs is beneficial for enhancing collaboration in EFL learning.

Further to this, previous research has also compared students' perceptions of using Google Docs for writing compared to traditional face-to-face methods and using a pencil and paper. For example, a large-scale study by 
Suwantarathip and Wichadee (2014) investigated the writing abilities of 5625 EFL students in Thailand, comparing those who collaborated on small-group writing assignments using Google Docs with those writing in traditional face-to-face classrooms. The findings indicated that those who collaborated using Google Docs had better writing performance than the face-to-face learning group. The findings also indicated the students had very positive attitudes toward using Google Docs, as it provided opportunities to share ideas with other students, promoted a collaborative learning environment, and increased student-student interactions, which, in turn, contributed to the students' perceived knowledge formation. Similar findings were also reported in a later study by Lin et al. (2016), who showed that EFL students had positive attitudes toward Google Docs, as it allowed them to learn more collaboratively, engage in problem-solving activities, and better understand the learning content. Finally, the students also recognized the importance of Google Docs as a real-time interactive tool for the collective editing of written tasks. Taken together, it appears that students have positive attitudes toward Google Docs due to its impact on the learning process.

Other studies have explored students' perceptions of the impact of Google Docs on their writing abilities. For example, Liu et al. (2014) conducted a longitudinal quantitative study to examine the impact of Google Docs on 210 EFL students' vocabulary and their perceptions of the experience. The findings from the vocabulary test showed that the participants' vocabulary knowledge improved significantly between the pre- and post-tests. The findings also indicated that the students had positive perceptions toward learning through Google Docs as a collaborative environment. Similar results were later confirmed in a study by Liu and Lan (2016), which compared the impact of individual and collaborative learning through Google Docs on the vocabulary of 65 tertiary-level students. The results indicated that the vocabulary of the two groups improved between the preand post-tests, but the collaborative learning group had gained more vocabulary knowledge than the individual learners. Additionally, the students generally maintained positive attitudes towards Google Docs as an interactive tool for learning. Overall, these results confirm that Google Docs can be conducive to language learning due to its collaborative nature, which impacts knowledge development.

\section{Method}

\subsection{Participants}

The total sample consisted of randomly-selected 164 Saudi EFL students (see Table 1). The participants were males $(n=62)$ and females $(n=102)$ from three different academic levels, studying Writing I, Writing II, and Academic Writing, at a public university in Saudi Arabia. Their ages ranged from 19-23 years old. Students are generally prepared to write short paragraphs and essays in English in these three different academic levels.

Table 1. Demographic information of the participants

\begin{tabular}{lll}
\hline Gender & Frequency & Percentage \\
\hline Male & 62 & $62 \%$ \\
Female & 102 & $38 \%$ \\
Total & 164 & $100 \%$ \\
\hline
\end{tabular}

The participants had varying previous experience with using Google Docs. All participants in this study had written between three and five texts using Google Docs during the second semester of the 2020 academic year (i.e., during the distance learning period due to the COVID-19 pandemic; see Table 2). These different texts were written both individually and in small groups, and teacher feedback was provided using the comments' function. The data collected was anonymous, and the participants were informed that their responses would remain confidential and be used for research purposes only.

Table 2. Students' previous experience and frequency of Google Docs use in the current semester

\begin{tabular}{lllll}
\hline \multicolumn{2}{l}{ Previous experience with Google Docs } & \multicolumn{4}{l}{ Frequency of Google Docs use this semester } \\
\hline Yes & No & Three times & Four times & Five times \\
\hline $45 \%$ & $55 \%$ & $38 \%$ & $39 \%$ & $23 \%$ \\
$100 \%$ & $100 \%$ & & \\
\hline
\end{tabular}

\subsection{Instrument}

The questionnaire, informed by previous studies in the field, consisted of 21 items exploring the participants' 
perceptions of using Google Docs in writing classes. The questionnaire is divided into three main sections: 1) perceptions of using Google Docs for writing (6 statements), 2) perceptions of interacting with the teacher using Google Docs (7 statements), and 3) perceptions of interacting with peers using Google Docs (8 statements). A three-point Likert scale (agree, neutral, disagree) was used to measure responses to all questionnaire items. The three-point Likert scale was used to encourage the respondents to complete the questionnaire and provide definite responses. Preston and Colman (2000) noted that respondents tend to have preference for scales with shorter options. Moreover, Matell and Jacoby (1971) stated that reliability and validity are independent of the number of scales and so they would not be affected by decreasing the number of response choices. Bourne et al. (2021) pinpointed that there is no strict rule to determine the appropriate number of responses, yet one important point to consider is that the scale should be organized symmetrically. That is, the questionnaire should consist of an equal number of positive and negative responses. In this study, the questionnaire was checked and evaluated by six experts in the EFL field to ensure the clarity and accuracy of the instrument, and it was then modified accordingly in line with their feedback. A pilot study was conducted with 34 students to establish its reliability. The Cronbach's alpha was 0.84 , thus indicating a high internal consistency reliability of items. The questionnaire was interpreted through the level of disagree (1.00-1.66), neutral (1.67-2.33), and agree (2.34-3.00).

\subsection{Procedure}

The questionnaire was created online using Google Forms, and it was distributed to all participants by the end of the second semester of the 2020 academic year. The link to the questionnaire was shared with the writing instructors at the university, who distributed the link to their students via email and WhatsApp. In total, 176 invitations were sent, and 164 students completed the questionnaire. Once the responses were collected, the Statistical Package for Social Sciences (SPSS) was used to calculate frequencies, the percentages, means and the standard derivations.

\section{Findings}

The present study aimed to explore EFL students' perceptions of using Google Docs in writing classes. One key objective was to elicit students' perceived benefits of using Google Docs to complete writing assignments and engage with teachers and peers through performing tasks with this interactive tool. This section reports the findings according to the three research questions.

\subsection{Perceptions of Using Google Docs in Writing Classes}

The first research question focused on students' overall perceptions of utilizing Google Docs as a learning platform for writing tasks (Table 3).

Table 3. Means, percentages, and standard deviations of students' perceptions of using Google Docs for writing tasks

\begin{tabular}{|c|c|c|c|c|c|c|}
\hline Item & Statement & Agree & Neutral & Disagree & Mean & SD \\
\hline 1 & Google Docs interface is easy to use. & $88 \%$ & $2 \%$ & $10 \%$ & 2.62 & 0.71 \\
\hline 2 & $\begin{array}{l}\text { The use of Google Docs made my learning experience more } \\
\text { engaging. }\end{array}$ & $76 \%$ & $11 \%$ & $14 \%$ & 2.57 & 0.75 \\
\hline 3 & $\begin{array}{l}\text { The use of Google Docs promoted a collaborative learning } \\
\text { environment. }\end{array}$ & $74 \%$ & $9 \%$ & $17 \%$ & 2.80 & 0.57 \\
\hline 4 & $\begin{array}{l}\text { Google Docs allowed me to access my writing assignments } \\
\text { anywhere and anytime. }\end{array}$ & $89 \%$ & $2 \%$ & $8 \%$ & 2.83 & 0.49 \\
\hline 5 & Google Docs platform is interesting to use for writing tasks. & $87 \%$ & $5 \%$ & $6 \%$ & 2.76 & 0.61 \\
\hline 6 & $\begin{array}{l}\text { The use of Google Docs increased my motivation to study } \\
\text { writing. }\end{array}$ & $84 \%$ & $10 \%$ & $6 \%$ & 2.78 & 0.60 \\
\hline
\end{tabular}

Table 3 shows that the mean scores ranged from 2.57 and 2.83, with standard deviations from 0.49 to 0.75 . Overall, most participants responded positively to nearly all the statements regarding the feasibility and use of Google Docs for completing writing tasks (Figure 1). The findings showed that the majority of the participants (88\%) agreed that Google Docs is easy to use, as well as that it not only encourages a collaborative learning experience but also makes the writing tasks more engaging $(88 \%, 76 \%$, and $74 \%$ agreed for statements 1,2 , and 3 , respectively). Indeed, $89 \%$ of the participants agreed that Google Docs is useful as it provides them with opportunities to access their assignments outside of the class time constraints, whereas only $8 \%$ indicated disagreement with this idea (statement 4). Furthermore, such accessibility seems to have positively affected the students' attitude and motivation, as $88 \%$ reported finding Google Docs interesting, and $84 \%$ reported that it 
increased their motivation to study writing (statements 5 and 6).

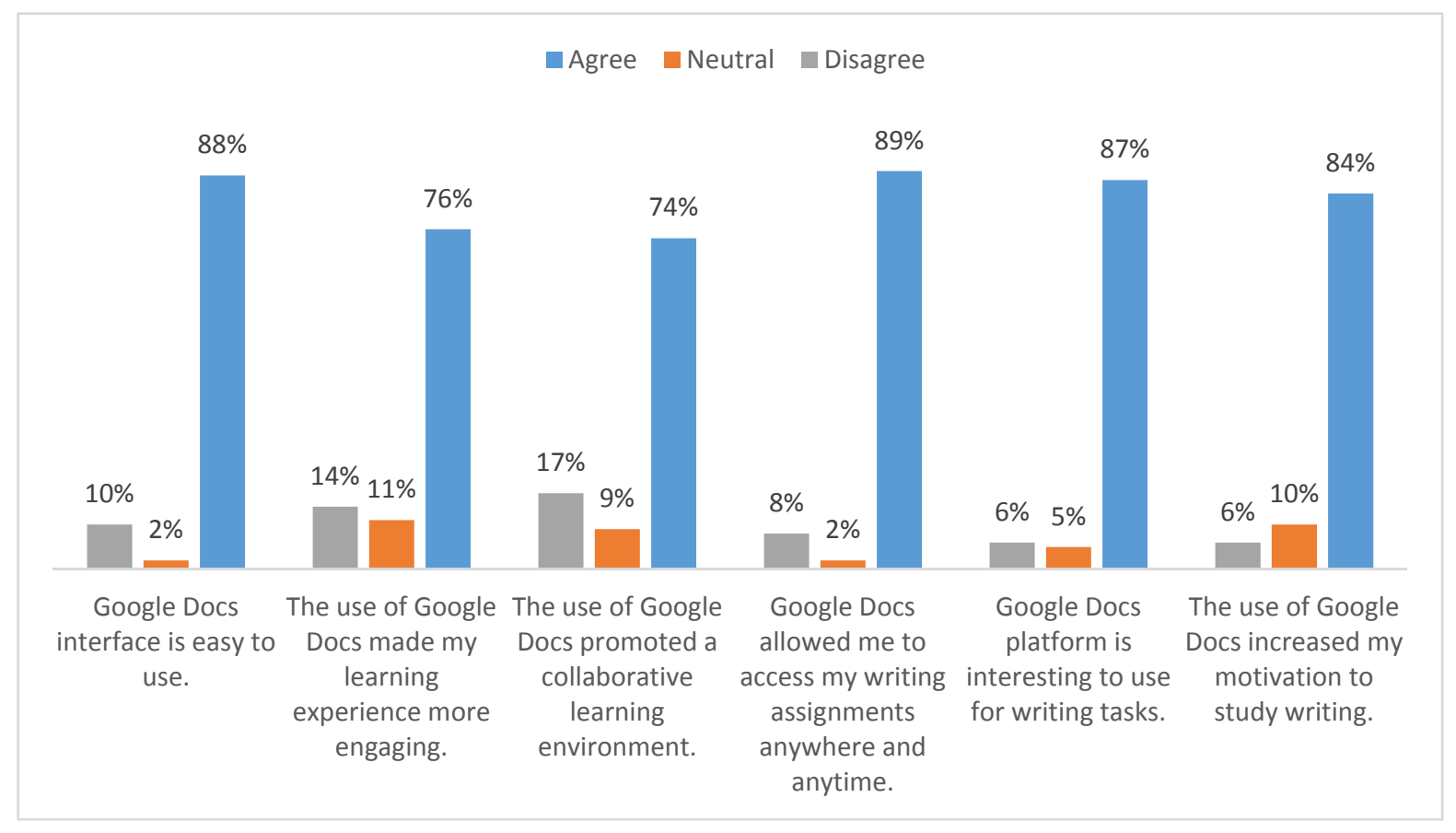

Figure 1. Students' perceptions of using Google Docs for writing tasks

\subsection{Perceptions of Using Google Docs to Interact with Teachers}

The second research question aimed to explore the students' perceptions of using Google Docs to interact with their teachers (Table 4).

Table 4. Means, percentages, and standard deviations of students' perceptions of using Google Docs to engage with teachers

\begin{tabular}{|c|c|c|c|c|c|c|}
\hline Item & Statement & Agree & Neutral & Disagree & Mean & SD \\
\hline 1 & The use of Google Docs increased interaction with the teacher. & $79 \%$ & $8 \%$ & $13 \%$ & 2.66 & 0.69 \\
\hline 2 & $\begin{array}{l}\text { The teacher's feedback on my Google Docs' writing } \\
\text { assignments was timely. }\end{array}$ & $67 \%$ & $13 \%$ & $20 \%$ & 2.68 & 0.70 \\
\hline 3 & $\begin{array}{l}\text { The use of Google Docs made it easier for me to understand } \\
\text { the teacher's feedback. }\end{array}$ & $87 \%$ & $3 \%$ & $10 \%$ & 2.88 & 0.43 \\
\hline 4 & $\begin{array}{l}\text { Google Docs made it easier for me to react to the teacher's } \\
\text { feedback appropriately. }\end{array}$ & $80 \%$ & $6 \%$ & $14 \%$ & 2.78 & 0.59 \\
\hline 5 & $\begin{array}{l}\text { I feel that teacher feedback via Google Docs helped me } \\
\text { improve my overall writing skills. }\end{array}$ & $82 \%$ & $10 \%$ & $8 \%$ & 2.61 & 0.73 \\
\hline 6 & $\begin{array}{l}\text { I feel more comfortable when submitting my writing tasks } \\
\text { using Google Docs compared to in-class paper submission. }\end{array}$ & $81 \%$ & $6 \%$ & $13 \%$ & 2.79 & 0.59 \\
\hline 7 & $\begin{array}{l}\text { I prefer to use Google Docs in the future to interact with my } \\
\text { writing teacher. }\end{array}$ & $91 \%$ & $4 \%$ & $5 \%$ & 2.87 & 0.45 \\
\hline
\end{tabular}

As shown in Table 4, the means generally ranged from 2.61 to 2.88 , with standard deviations from 0.43 to 0.73 . In general, the responses indicated an overall agreement among the participants that Google Docs is an effective tool for interacting with teachers (Figure 2). For example, $79 \%$ of the subjects agreed that Google Docs allowed more interactive engagement with the teachers (statement 1 ). Similarly, $67 \%$ of the participants responded that the teacher feedback on the assignments was timely, whereas only $20 \%$ disagreed with this statement (statement 2). Moreover, $87 \%$ indicated that the feedback provided was easy to understand, and, thus, they were able to respond to the feedback appropriately (statements 3 and 4). The participants' responses suggest that Google Docs contributed to developing their writing skills ( $82 \%$ agreed with statement 5 , whereas only $8 \%$ disagreed). 
Furthermore, according to $81 \%$ of the participants, submitting writing assignments via Google Docs was more comfortable compared to traditional in-class pen-and-paper written tasks, whereas $13 \%$ showed disagreement with this statement. Finally, the vast majority of the participants (91\%) indicated a preference for using Google Docs in the future to engage with their teachers.

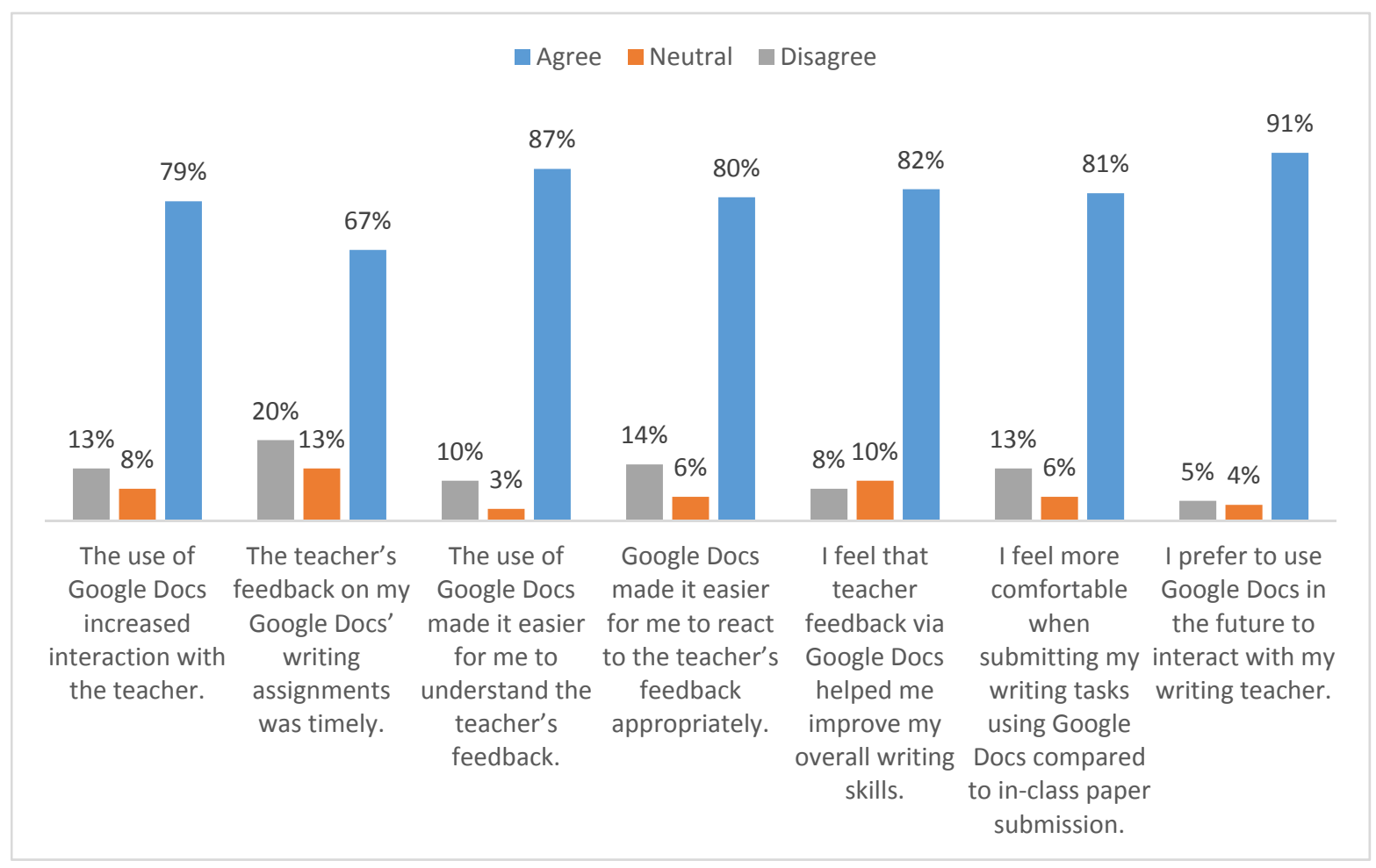

Figure 2. Students' perceptions of using Google Docs to engage with teachers

\subsection{Perceptions of Using Google Docs to Interact with Peers}

The third research question concerned students' perceptions of using Google Docs to interact with peers (Table $5)$.

Table 5. Means, percentages, and standard deviations of students' perceptions of using Google Docs to engage with peers

\begin{tabular}{|c|c|c|c|c|c|c|}
\hline Item & Statement & Agree & Neutral & Disagree & Mean & SD \\
\hline 1 & $\begin{array}{l}\text { The use of Google Docs increased participation and } \\
\text { interaction with my classmates. }\end{array}$ & $82 \%$ & $10 \%$ & $8 \%$ & 2.68 & 0.69 \\
\hline 2 & $\begin{array}{l}\text { The use of Google Docs made it easier to create texts with } \\
\text { classmates. }\end{array}$ & $84 \%$ & $6 \%$ & $10 \%$ & 2.84 & 0.49 \\
\hline 3 & Google Docs helped me share ideas with the other students. & $83 \%$ & $12 \%$ & $5 \%$ & 2.78 & 0.57 \\
\hline 4 & $\begin{array}{l}\text { Google Docs provided opportunities to engage in constructive } \\
\text { discussions. }\end{array}$ & $90 \%$ & $3 \%$ & $7 \%$ & 2.83 & 0.52 \\
\hline 5 & $\begin{array}{l}\text { I feel comfortable seeing other students edit the content I have } \\
\text { posted. }\end{array}$ & $76 \%$ & $17 \%$ & $7 \%$ & 2.53 & 0.81 \\
\hline 6 & $\begin{array}{l}\text { The feedback and editing from peers were useful for } \\
\text { improving my writing skill. }\end{array}$ & $69 \%$ & $9 \%$ & $22 \%$ & 2.37 & 0.87 \\
\hline 7 & $\begin{array}{l}\text { Google Docs influenced groups' collaborative experiences } \\
\text { positively. }\end{array}$ & $74 \%$ & $5 \%$ & $21 \%$ & 2.57 & 0.78 \\
\hline 8 & $\begin{array}{l}\text { I would like to use Google Docs in the future to interact with } \\
\text { my classmates in writing classes. }\end{array}$ & $93 \%$ & $2 \%$ & $5 \%$ & 2.71 & 0.67 \\
\hline
\end{tabular}


Table 5 shows that the means ranged from 2.53 to 2.84 with standard deviations between 0.49 and 0.87 . The participants' responses showed positive perceptions of using Google Docs as an online platform to engage with peers (Figure 3).

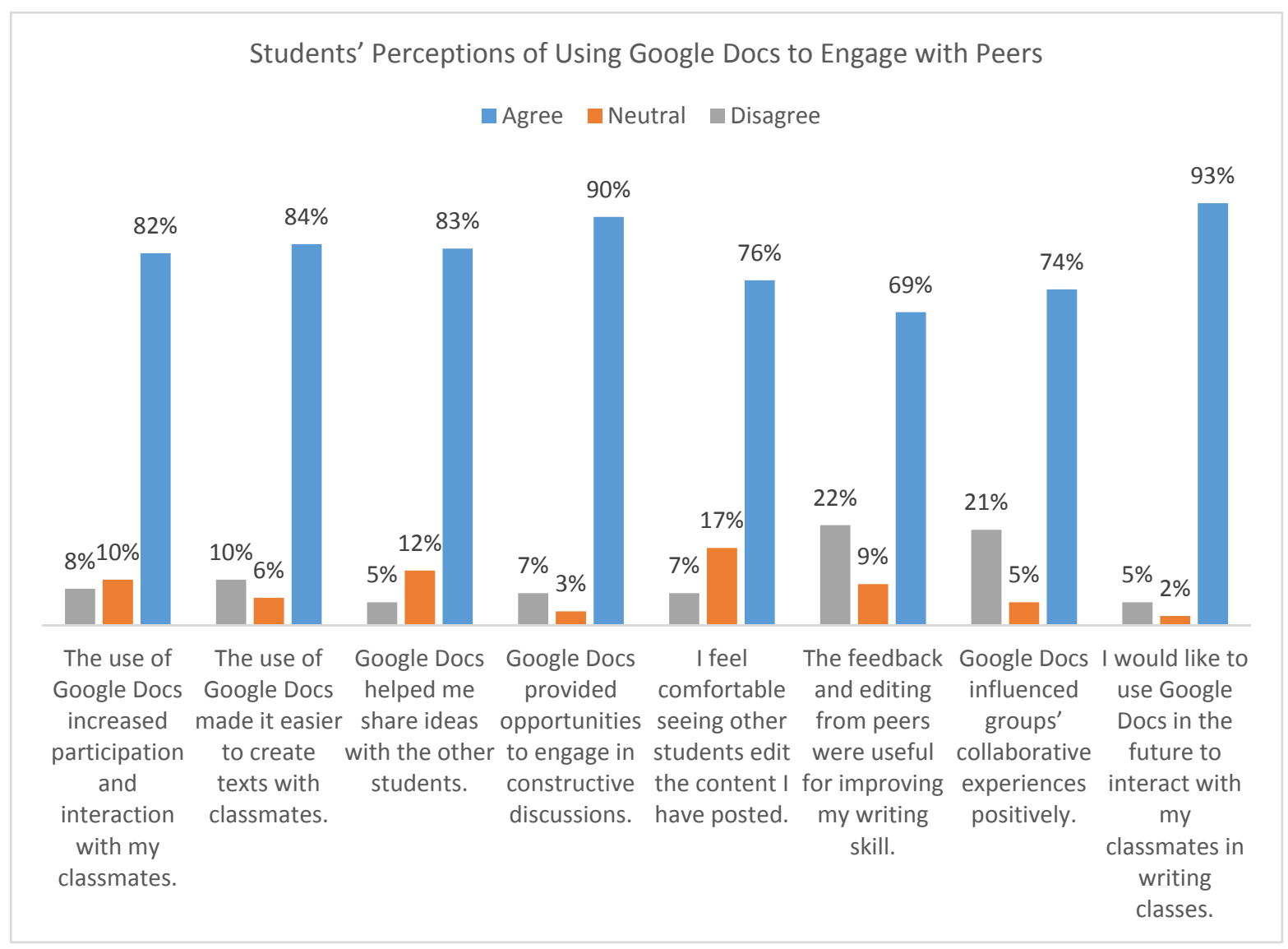

Figure 3. Students' perceptions of using Google Docs to engage with peers

According to the responses, $82 \%$ agreed that Google Docs allowed for more interactive participation with their peers (statement 1). Moreover, $84 \%$ of the participants found Google Docs useful for jointly creating texts and sharing ideas with peers and reported that it provided opportunities for constructive negotiations (statements 2,3 , and 4). In terms of their perceptions of collective engagement, although $76 \%$ of the participants reported feeling comfortable seeing other students' editing the parts they had written (statement 5), only $69 \%$ found the feedback provided by peers useful, whereas $22 \%$ felt that the feedback was not constructive (statement 6 ). Furthermore, the participants thought that Google Docs positively influenced their collaborative writing experience (74\% agreed, whereas $21 \%$ disagreed with statement 7 ). Overall, nearly all the participants (93\%) indicated a willingness to use Google Docs in the future to engage with peers during writing tasks.

\section{Discussion}

The findings of this study have demonstrated the positive perceptions of Saudi tertiary-level students toward Google Docs as an interactive learning tool in writing classes. In particular, the results showed that the participants found Google Docs interesting, easy to use, and beneficial for enhancing collaborative learning. Such findings are in line with the study of Ishtaiwa and Aburezeq (2015), who reported that students have positive attitudes toward Google Docs as an entertaining and useful learning tool. The current study's findings also highlighted that the accessibility of Google Docs enhanced the participants' motivation during writing tasks. Indeed, this may be attributable to the user-friendly features of Google Docs that promote high levels of collaboration and participation ( $\mathrm{Li}, 2017)$.

This study also demonstrated the students' positive perceptions of Google Docs as an online platform for interacting with teachers. Indeed, the participants reported that Google Docs provided them with the opportunity to engage with teachers more actively, as well as that the feedback was timely and easy to understand. Similar 
findings were reported by Jeong (2016), who found that Google Docs allowed participants to receive immediate feedback from the teacher and that the feedback was easily understood, which enabled students to react to the feedback appropriately. One explanation for such a finding could be that Google Docs provides the students with opportunities to examine feedback beyond the confines of traditional classroom settings carefully. Furthermore, in this study, such reciprocal interactions appear to have contributed to the participants' perceived development of their writing skills. Indeed, another key finding reported in this study is that the participants preferred submitting their writing assignments using Google Docs compared to traditional paper submission methods, which may be due to a number of factors. For instance, Google Docs provides features that can help writers improve their writing, such as grammar, spelling, and punctuation auto-correction. These features allow the students to produce relatively better writing, as these features are not easily available for in-class handwriting. Another feature is that Google Docs may provide opportunities for students to compare their own work with that of their peers and engage in discussions (Ishtaiwa \& Aburezeq, 2015).

Concerning the students' perceptions of using Google Docs to interact with peers, the findings showed students' agreement that Google Docs allowed for more interactive participation with their classmates. This result is in line with Al-Chibani (2016), who reported that students perceived Google Docs as an interactive tool that provides opportunities for them to communicate with each other. Another finding in the current study is that Google Docs was perceived as useful for collaborative tasks, as it helped the students co-construct knowledge, share ideas, and engage in constructive negotiations. Similar findings were also reported by Kesseler et al. (2012), who reported that students appreciated the collaborative work, as well as Suwantarathip and Wichadee (2014), who indicated that Google Docs provided opportunities to exchange ideas, promoted collaborative learning, and enhanced student-student interaction, thus contributing to the students' perceived knowledge construction. Furthermore, Lin et al. (2016) found that Google Docs helped students better understand the learning content and that the students appreciated Google Docs as a real-time interactive tool. Finally, the present results also highlighted that, despite feeling comfortable seeing their written work edited by peers, some students perceived that the feedback received was not constructive. This finding is unsurprising and quite common in peer feedback, especially in EFL contexts where teacher-centered classes prevail. Indeed, in such contexts, students tend to rely on teacher commentary, are skeptical about peers' ability to provide valid comments, or may not regard their peers as a legitimate audience (Ferris, 2003).

\section{Conclusion}

To conclude, this study aimed to explore tertiary-level students' perceptions of their experience with Google Docs as an interactive learning tool in writing classes. The findings showed that students found Google Docs useful and interesting, as well as that it enhanced their interactions with both teachers and classmates. In general, the findings highlight the significance of integrating Google Docs into EFL writing classes, as it promotes collaborative learning and allows students to engage more effectively with the feedback of both teachers and peers. Although the findings contribute to EFL writing, the study has some limitations. For example, the study was conducted at one university in Saudi Arabia. Future studies may consider cross-sectional studies with larger samples from different universities. Another limitation is the merely descriptive nature of this study which makes the findings ungeneralizable to the target population. Thus, it may be worthwhile for researchers to conduct interviews in future work to gain more insights into the participants' experience with Google Docs. Moreover, the present study explored both male and female students' perceptions. Future studies may consider examining the perceptions of the participants according to gender.

\section{Acknowledgements}

The author expresses his appreciation to the Deanship of Scientific Research at King Saud University, Saudi Arabia, and the Research Center in the College of Languages \& Translation for offering their support for this article.

\section{References}

Al-Chibani, W. (2016). Impact on student motivation of integrating Google docs within a remedial English writing class (pp. 333-340). ICICTE 2016 Proceedings.

Alharbi, M. A. (2019). Saudi Arabia EFL university students' voice on challenges and solution in learning academic writing. Indonesian Journal of Applied Linguistics, 8(3), 576-587. https://doi.org/10.17509/ijal.v8i3.15276

Bourne, V., James, A., Wilson-Smith, K, \& Fairlamb, S. (2021). Understanding quantitative and qualitative research in psychology a practical guide to methods, statistics, and analysis. Oxford University Press. 
Chinnery, G. (2008). On the net you've got some gall: Google-assisted language learning. Language Learning and Technology, 12(1), 3-11. http://dx.doi.org/10125/44126

Crossley, S. A., Kyle, K., \& McNamara, D. S. (2016). The development and use of cohesive devices in L2 writing and their relations to judgments of essay quality. Journal of Second Language Writing, 32, 1-16. https://doi.org/10.1016/j.jslw.2016.01.003

Ferris, D. R. (2003). Response To Student Writing: Implications for Second Language Students (1st ed.). Routledge. https://doi.org/10.4324/9781410607201

Ishtaiwa, F. F., \& Aburezeq, I. M. (2015). The impact of Google Docs on student collaboration: A UAE case study. Learning, Culture and Social Interaction, 7, 85-96. https://doi.org/10.1016/j.lcsi.2015.07.004

Javadi-Safa, A. (2018). A brief overview of key issues in second language writing teaching and research. International Journal of Education and Literacy Studies, 6(2), 12-25. https://doi.org/10.7575/aiac.ijels.v.6n.2p.15

Jeong, K. O. (2016). A study on the integration of Google Docs as a web-based collaborative learning platform in EFL writing instruction. Indian Journal of Science and Technology, 9(39), 1-7. https://doi.org/10.17485/ijst/2016/v9i39/103239

Jiang, W., \& Eslami, Z. R. (2021). Effects of computer-mediated collaborative writing on individual EFL writing performance. Computer Assisted Language Learning, 1-30. https://doi.org/10.1080/09588221.2021.1893753

Kessler, G., Bikowski, D., \& Boggs, J. (2012). Collaborative writing among second language learners in academic web-based projects. Language Learning \& Technology, 16(1), 91-109.

Khalil, Z. M. (2018). EFL students' perceptions towards using Google Docs and Google Classroom as online collaborative tools in learning grammar. Applied Linguistics Research Journal, 2(2), 33-48. https://doi.org/10.14744/alrj.2018.47955

Lee, K. Y., \& Hassell, D. G. (2021). Students' Attitudes and Preferences Towards Google Docs as a Collaborative Writing Platform. International Journal of Computer-Assisted Language Learning and Teaching, 11(2), 1-15. https://doi.org/10.4018/IJCALLT.2021040101

Li, M. (2018). Computer-mediated collaborative writing in L2 contexts: An analysis of empirical research. Computer Assisted Language Learning, 31(8), 882-904. https://doi.org/10.1080/09588221.2018.1465981

Lin, Y. T., Chang, C. H., Hou, H. T., \& Wu, K. C. (2016). Exploring the effects of employing Google Docs in collaborative concept mapping on achievement, concept representation, and attitudes. Interactive Learning Environments, 24(7), 1552-1573. https://doi.org/10.1080/10494820.2015.1041398

Liu, S., \& Lan, Y. (2016). Social constructivist approach to web-based EFL learning: Collaboration, motivation, and perception on the use of Google docs. Educational Technology \& Society, 19(1), 171-186.

Liu, S., Lan, Y., \& Ho, C. (2014). Exploring the relationship between self-regulated vocabulary learning and web-based collaboration. Educational Technology \& Society, 17(4), 404-419.

Matell, M. S., \& Jacoby, J. (1971). Is there an optimal number of alternatives for Likert scale items? Study 1: reliability and validity. Educational and Psychological Measurement, 31, 657-674. https://doi.org/10.1177/001316447103100307

Mudawe, O. M. N. (2018). Google docs: potentials and promises for scaffolding supervisory pedagogical practices of EFL/ESL students' writing dissertation. Journal of Applied Linguistics and Language Research, $5(2), 192-206$.

Perron, B. E., \& Sellers, J. (2011). A review of the collaborative and sharing aspects of Google Docs. Research on Social Work Practice, 21, 489-490. https://doi.org/10.1177/1049731510391676

Preston, C. C., \& Colman, A. M. (2000). Optimal number of response categories in rating scales: Reliability, validity, discriminating power, and respondent preferences. Acta Psychologica, 104(2000), 1-15. https://doi.org/10.1016/S0001-6918(99)00050-5

Ransdell S., \& Barbier M. L. (2002) An introduction to new directions for research in 12 writing. In S. Ransdell \& M. L. Barbier (Eds.), New directions for research in L2 writing. studies in writing (vol 11). Springer, Dordrecht. https://doi.org/10.1007/978-94-010-0363-6

Reyna, J. (2013). The importance of visual design and aesthetics in e-learning. Training \& Development, 40(5), 
$28-31$.

Seyyedrezare, Z. S., Ghonsooly, B., Shahriarı, H., \& Fatemı, A. H. (2016). A mixed methods analysis of the effect of google docs environment on EFL learners' writing performance and causal attributions for success and failure. Turkish Online Journal of Distance Education, 17(3), 90-110. https://doi.org/10.17718/tojde.34418

Suvin, S. (2020). Complexities of writing skill at the secondary level in Bangladesh education system: A quantitative case study analysis. English Language Teaching, 13(12), 65-75. https://doi.org/10.5539/elt.v13n12p65

Suwantarathip, O., \& Wichadee, S. (2014). The effects of collaborative writing activity using Google Docs on students' writing abilities. Turkish Online Journal of Educational Technology, 13(2), 148-156.

Woodrich, M., \& Fan, Y. (2017). Google Docs as a tool for collaborative writing in the middle school classroom. Journal of Information Technology Education: Research, 16(1), 391-410. https://doi.org/10.28945/3870

Zhou, W., Simpson, E., \& Domizi, D. P. (2012). Google Docs in an out-of-class collaborative writing activity. International Journal of Teaching and Learning in Higher Education, 24(3), 359-375.

\section{Copyrights}

Copyright for this article is retained by the author, with first publication rights granted to the journal.

This is an open-access article distributed under the terms and conditions of the Creative Commons Attribution license (http://creativecommons.org/licenses/by/4.0/). 